Monika Ostapiuk*, Jarosław Bieniaś and Barbara Surowska

\title{
Analysis of the bending and failure of fiber metal laminates based on glass and carbon fibers
}

https://doi.org/10.1515/secm-2017-0180

Received May 26, 2017; accepted October 16, 2017; previously published online December 6, 2017

\begin{abstract}
The purpose of this paper is to investigate the mechanisms of cracking and failure in fiber metal laminates (FMLs) subjected to 3-point bending. Two types of laminates, based on the glass/epoxy and carbon/epoxy composites, were selected for the study. The paper presents the failures of matrix and fibers as well as the effects of different thicknesses of metal layers on the tested laminates. The mechanisms of failure observed for the two tested types of fibers with uniform thickness of aluminum sheets seem similar. The results demonstrate that the tested laminates exhibit the following failure modes: fiber breakage, matrix cracking, fiber/matrix debonding, delamination, and anodic layer failure. Given the behavior of aluminum under the compressive and tensile stresses, the aluminum layer acts as a barrier preventing FML failure during bending. In addition to aluminum layer thickness, the fiber type and composite layer directions are also important factors to be considered.
\end{abstract}

Keywords: bending; carbon fibers; failure; FML; glass fibers.

\section{Introduction}

Over the last few decades, many researchers dealing with aircraft applications have developed new materials while ensuring low weight and good mechanical properties. One group of such materials are fiber metal laminates (FMLs). They are a new type of hybrid composites, consisting of thin metal layers bonded with polymeric composite material reinforced with glass, carbon, or Kevlar fibers [1]. These laminates combine the good properties of metals, such as ductility and impact and damage tolerance, with the advantages of fiber composite materials, including

*Corresponding author: Monika Ostapiuk, Department of Materials Engineering, Lublin University of Technology, Nadbystrzycka 36, 20-618 Lublin, Poland, e-mail: m.ostapiuk@pollub.pl Jarosław Bieniaś and Barbara Surowska: Department of Materials Engineering, Lublin University of Technology, Nadbystrzycka 36, 20-618 Lublin, Poland high specific strength and stiffness, good corrosion, and fatigue resistance. FMLs are widely used in the design of critical aircraft parts, such as lower and upper wings as well as fuselage and tail sections [2]. The widespread use of FMLs is due to their unique properties resulting from the application of composite material and metal layers that ensure high shear strength. The interlaminar bond strength between the metal and the polymer layer is of fundamental importance. This interfacial joint enables the transfer of mechanical loads between the constituent materials, thereby determining the entire efficiency of a given structure. In particular, when a through-thickness crack initiates and propagates in the metal layers, the stress sustained by these layers is transferred to the unbroken fibers in the composite layers [3-5].

Due to the fact that, after cracking, the fibers remain intact and bridge the crack, the crack opening is constrained. Consequently, the force (stress intensity factor) of the crack propagation in the metal layers is reduced, leading to a low crack growth rate. Given the above, the mechanical properties of FMLs have been investigated by many researchers, institutes, and aviation industry companies. The mechanical behavior of composite materials is generally determined based on the results of the tensile, compressive, and bending strength tests. The continuous fiber-reinforced composites are often subjected to the bending load rather than to the axial load; hence, the bending tests are highly desirable as a means of describing the properties of composite materials. In bending, half of a beam is subjected to compression while its other half is under tension; if the beam is elastic, the maximum tensile and compressive stresses are equal in magnitude. Consequently, the composite materials may undergo bending failure due to tensile or compressive stresses [6]. Many researchers resort to bending tests because the information they provide about the mechanical properties of the composite laminates is much more useful than that obtained by other tests, for instance, Charpy impact tests. In general, the failure of a composite structure will involve some type of fiber or translaminar cracking mode. In aircraft applications, failure is usually caused by the compression mechanisms, mainly because most aircraft parts are designed to withstand flexural loads [7]. The standards normally describe apparent flexural stiffness and strength as well as bending force; the causes of damage 
are usually determined based on structure examination. However, the standard interlaminar shear strength [8] is determined by only considering the data obtained from cases of shear failure. Based on the standards, we can determine the elastic properties of structures corresponding to their behavior under tension and compression. This was observed by Jones $[9,10]$, who determined the elastic moduli and maximum normal stresses in the regions subjected to tension and compression by 3- and 4-point bending tests from the equilibrium and constitutive relations. Similar analyses were performed by Mujika and Carbajal [11, 12], who applied the same procedures. No earlier study has been found where shear stress distributions and different tensile and compressive behaviors are investigated [12].

As a hybrid laminated structure, the FML has a complex multi-interface system that includes fiber-matrix and matrix-metal interfaces. However, these interfaces at different layers of a glass reinforced epoxy-aluminum laminate (GLARE) material are sensitive to interfacial debonding by shear load due to bending or torsion [13]. Delamination is one of the critical failure mechanisms occurring in fibrous composites [14], and the propagation of local debonding between the fiber and matrix results in a failure of the entire structure during its operation [15]. A relatively accurate assessment of the interlaminar shear failure resistance provides some information about quality control and material screening [16].

The purpose of the present paper is to investigate the bending and failure of FMLs based on the aluminum and polymer layers with glass and carbon fibers by 3-point bending tests. The examination of the matrix and fiber failures investigates the role of different thicknesses of metal layers. Apart from investigating the role of different fiber configurations in the polymer layer, the study also examines the phenomena between the polymer and anodic layer, which may cause delamination. In addition, the paper examines the role and behavior of the interface between the aluminum and the polymer composite layer.

\section{Materials and methods}

The laminates investigated in this study were FMLs made of high-strength aluminum alloy sheets 2024 T3 (Al4CuMg1) with a glass fiber-reinforced polymer (Al/GFRP/Al) and a carbon fiber-reinforced polymer (Al/CFRP/Al). The aluminum sheets came in two thicknesses: 0.3 and $0.5 \mathrm{~mm}$. The composite layers consisting of unidirectional prepregs (Hexcel, USA) were based on R-type high-strength glass fibers (one prepreg layer had a thickness of $0.25 \mathrm{~mm}$ ) and carbon fibers AS7J (thickness of one prepreg layer was $0.13 \mathrm{~mm}$ ) with an epoxy resin matrix. The nominal fiber content in polymer composite layer was about 60 vol.\%. The metal sheet surfaces were prepared by chromic acid anodizing (CAA). Next, the surfaces of the anodized aluminum sheets were treated with an epoxybased primer (3M USA) to prevent oxidation (Figure 1A), thereby enhancing the durability of the bond between the polymer layers (glass/epoxy and carbon/epoxy) and the aluminum sheets. The surface pretreatment was followed by the lay-up process, in which the FMLs were produced by autoclaving (Scholz Maschinenbau, Germany) at the Department of Materials Engineering at the Lublin University of Technology. The parameters applied in the process were as follows: curing temperature $-135^{\circ} \mathrm{C}$; pressure - $450 \mathrm{kPa}$; vacuum - $80 \mathrm{kPa}$; and heating and cooling rate $-2 \mathrm{~K} / \mathrm{min}$. The temperature and pressure conditions were maintained under control during the process. The above parameters significantly prevented the occurrence of defects, such as voids or delamination. A chart illustrating the curing parameters is shown in Figure 1B. The configuration and thickness layers of individual FMLs are given in Table 1.

The 3-point bending tests in accordance with the specifications of the CRAG 3-point were conducted using MTS Insight. The test specimens had a length of $100 \mathrm{~mm}$

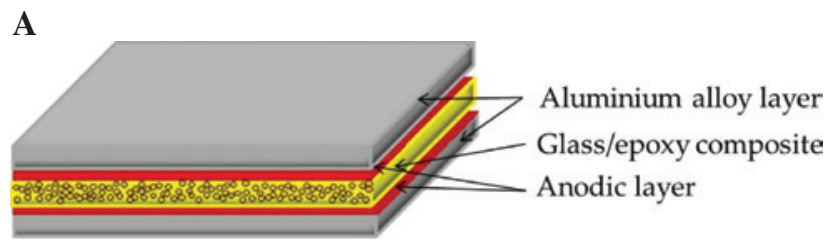

\section{B}

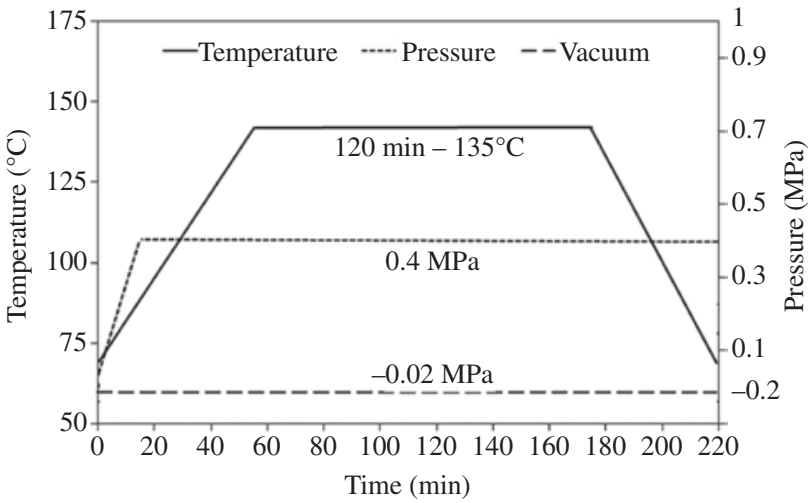

Figure 1: Aluminum sheets treated with an epoxy-based primer to prevent oxidation (A) and chart illustrating curing parameters (B). (A) The schematic view of the fiber metal laminate (FML) layers and (B) the chart showing the autoclave process. 
Table 1: The composition of the fiber metal laminates.

\begin{tabular}{|c|c|c|c|c|c|c|}
\hline Fiber metal laminates & $\begin{array}{l}\text { Thickness of one } \\
\text { aluminum sheet [mm] }\end{array}$ & $\begin{array}{r}\text { Number of } \\
\text { composite layers }\end{array}$ & $\begin{array}{l}\text { Thickness of the } \\
\text { composite [mm] }\end{array}$ & $\begin{array}{r}\text { Fiber } \\
\text { direction }\left[^{\circ}\right]\end{array}$ & MVF & $\begin{array}{r}\text { Thickness } \\
\text { of the FML [mm] }\end{array}$ \\
\hline $\mathrm{Al} / \mathrm{GFRP} / \mathrm{Al} 0.3[0]$ & 0.3 & 2 & 0.5 & 0 & 0.53 & 1.1 \\
\hline $\mathrm{Al} / \mathrm{CFRP} / \mathrm{Al} 0.3[0]$ & 0.3 & 4 & 0.5 & 0 & 0.53 & 1.1 \\
\hline $\mathrm{Al} / \mathrm{GFRP} / \mathrm{Al} 0.5[0]$ & 0.5 & 2 & 0.5 & 0 & 0.66 & 1.5 \\
\hline $\mathrm{Al} / \mathrm{CFRP} / \mathrm{Al} 0.5[0]$ & 0.5 & 4 & 0.5 & 0 & 0.66 & 1.5 \\
\hline $\mathrm{Al} / \mathrm{GFRP} / \mathrm{Al} 0.5[ \pm 45]$ & 0.5 & 2 & 0.5 & \pm 45 & 0.66 & 1.5 \\
\hline $\mathrm{Al} / \mathrm{CFRP} / \mathrm{Al} 0.5[ \pm 45]$ & 0.5 & 4 & 0.5 & \pm 45 & 0.66 & 1.5 \\
\hline Al/GFRP/Al 0.5 [0/90] & 0.5 & 2 & 0.5 & $0 / 90$ & 0.66 & 1.5 \\
\hline Al/GFRP/Al 0.5 [90/0] & 0.5 & 4 & 0.5 & $90 / 0$ & 0.66 & 1.5 \\
\hline $\mathrm{Al} / \mathrm{CFRP} / \mathrm{Al} 0.5$ [0/90] & 0.5 & 4 & 0.5 & $0 / 90$ & 0.66 & 1.5 \\
\hline $\mathrm{Al} / \mathrm{CFRP} / \mathrm{Al} 0.5[90 / 0]$ & 0.5 & 4 & 0.5 & $90 / 0$ & 0.66 & 1.5 \\
\hline
\end{tabular}

MVF, Metal volume fraction.

and a width of $10 \mathrm{~mm}$. The 3-point bending was performed at room temperature. Figure 2 shows a schematic design of the test stand and the dimensions of the supports.

The 3-point bending tests were performed at a crosshead displacement set to $5 \mathrm{~mm} / \mathrm{min}$; the test was stopped when a specimen reached a $25-\mathrm{mm}$ deflection. The load was increased uniformly until a specimen's failure or to determine standard deflection. If a specimen failed before reaching the fixed arrow, its bending strength was defined as the maximum bending stress carried by the specimen. This is calculated from the formula

$$
\sigma=\frac{\mathrm{Mg}}{\mathrm{W}}=\frac{\frac{F l}{4}}{\frac{b h^{2}}{6}}=\frac{3}{2} \frac{F l}{b h^{2}}
$$

where

$F$ is the maximum load before failure $[\mathrm{N}]$, $h$ is the thickness of the specimen [mm], $b$ is the width of the specimen [mm], and $l$ is the distance between the supports, $[\mathrm{mm}]$.

If the sample does not undergo failure before reaching the deflection arrow $s_{c}$, the properties of the material are defined by a so-called stress at a specific deflection

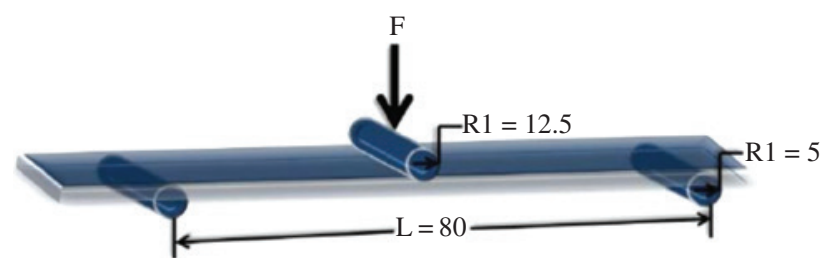

Figure 2: The schematic design of the test stand with the dimensions of the supports. arrow $\sigma$. In other words, it is the highest normal (bending) stress of the specimen at the deflection $\mathrm{s}_{\mathrm{c}}$. A value of $F$ is the force measured at the deflection $\mathrm{s}_{\mathrm{c}}$. The value $\sigma_{\mathrm{fc}}$ is an arbitrary value (standard deviation) due to the fact that the properties of many materials at $\mathrm{s}_{\mathrm{c}}$ are beyond the limit of applicability of Hooke's law.

The 3-point bending tests were followed by a failure analysis of the specimens with respect to the failure modes. First, a macroscopic observation of the specimens was performed. Next, a selection of the fractured specimens from the bending test was submitted for microscopic analysis to examine the failure inside the FMLs. The examination was performed by optical microscopy (Nikon MA200, Japan) with Nomarsky contrast and scanning electron microscopy (SEM) (Zeiss Ultra Plus). The specimens for SEM were chromium-coated to avoid any charging effects due to the insulating properties of the glass fibers and the polymeric matrix. The examination was conducted to gain insights into the nature of the interaction/bonding between the polymer layer/ aluminum sheets and the failure of the matrix/fibers. The specimens were also examined for any presence of voids in the structure as it could reduce the quality of the specimens.

\section{Results and discussion}

\subsection{3-Point bending test}

The 3-point bending test was performed to investigate both the properties of the FMLs and the failure of the entire structure consisting of metal sheets and composite material with glass and carbon fibers. 


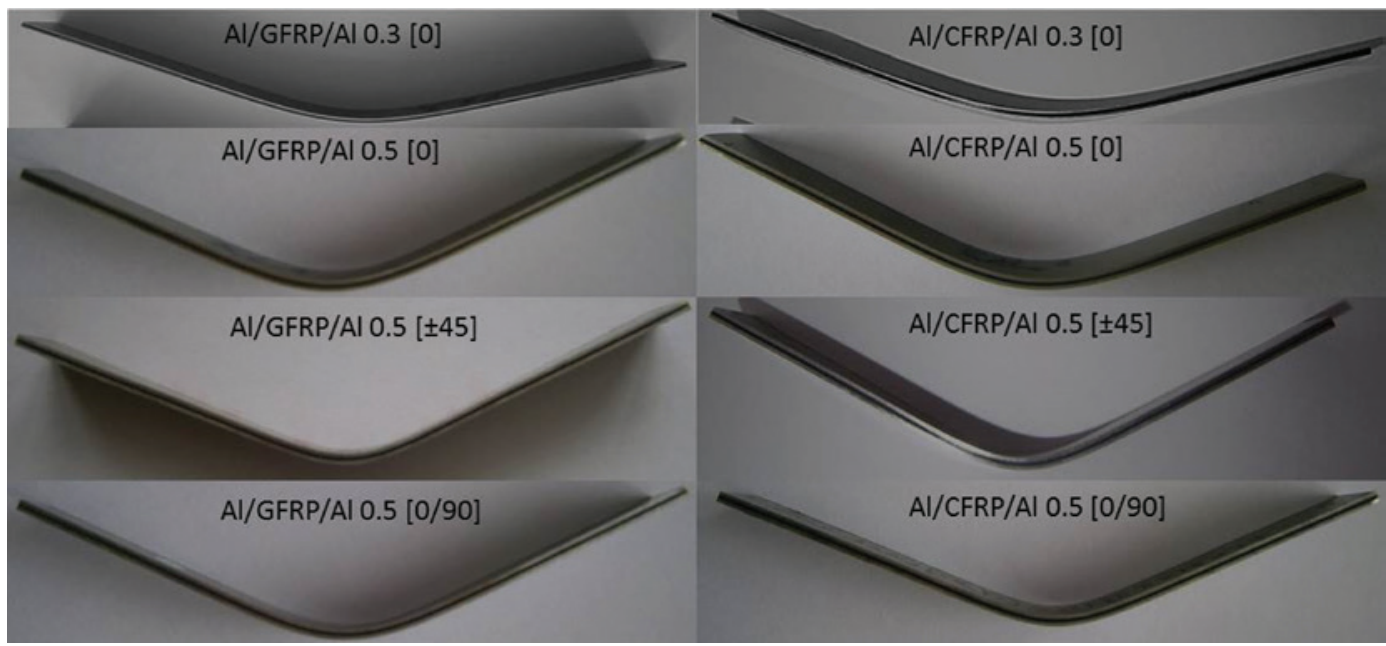

Figure 3: The FML samples after the 3-point bending test.

Figure 3 shows the specimens after the 3-point bending test. The macroscopic observation did not reveal any signs of failure or delamination between the aluminum sheets and the polymer composite layers. All specimens exhibited a similar deflection in the central part to which the load was applied.

Figure 4 shows the stress-displacement curves obtained by 3-point bending for different fiber configurations in the FMLs. As already mentioned, the objectives of representing nominal parameters are to compare the specimens with different thicknesses and to determine their damage tolerance. The curves visibly demonstrate the effects of stress and displacement on the strength of the tested FMLs. Two types of curves can be distinguished
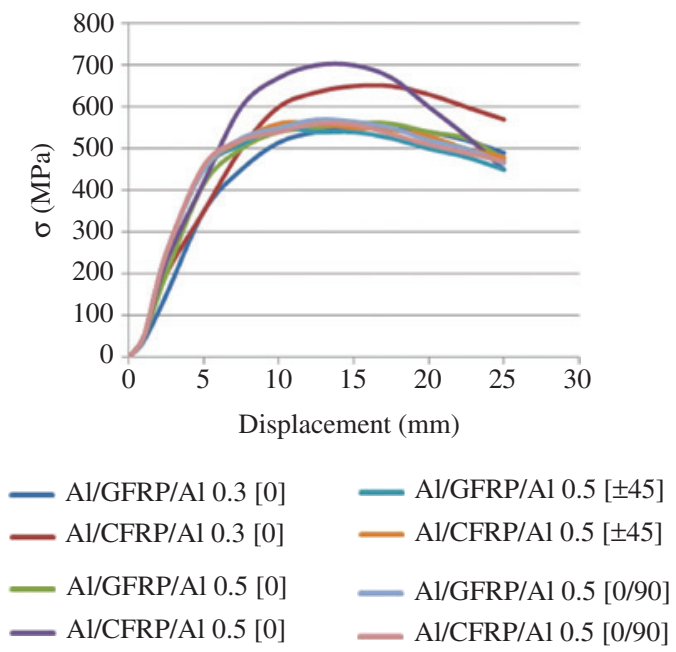

Figure 4: The stress-displacement curves of the FMLs based on the glass and carbon fibers in the [0], $[ \pm 45],[0 / 90]$, and [90/0] layer configurations. regarding the mechanical properties of the FML constituent materials. The first, lower linear part corresponds to the elastic response of the constituent materials and the knee point denotes the yield limit of the aluminum layers; the upper range marks the behavior of the glass and carbon fiber composite. All tested specimens changed their shape in a similar way (Figure 3). Obviously, the central layer changed that. No tested specimen revealed cracking in its entire cross-section.

As the deformation proceeded, the delamination shifted toward the support point of the fibers during the bending test. In addition to this, further deformation and stresses contributed to fiber breakage. Thus, the maximum fiber strains affected their maximum flexural stress during bending. Despite a permanent set of all specimens due to the plasticity of the aluminum, no delamination of the FML layers can be observed.

Glass fiber laminates showed the maximum bending stress of about $560 \mathrm{MPa}$ in all configurations of fiber layers. In contrast, the maximum bending stress of composites based on carbon fibers was about $700 \mathrm{MPa}$ for the $0^{\circ}$ fibers regardless of the applied aluminum layer thickness. There were no differences between the [0/90] and [90/0] fibers when the first layer was placed under compression. Both types of composite laminates showed considerable damage tolerance due to the different intrinsic and extrinsic mechanisms of failure. This will be analyzed later in the paper. Accordingly, the significant increase in the mechanical strength of the FML can be associated with high damage tolerance. Additionally, the figures clearly revealed that the behavior of the two laminates was determined by the properties of both the constituent materials and their interfaces. 
Table 2: Results of the 3-point bending strength test.

\begin{tabular}{lrrrrrr}
\hline Sample type & $\begin{array}{c}\text { Thickness of the } \\
\text { aluminium layers [mm] }\end{array}$ & MVF & $\begin{array}{c}\text { Configuration } \\
\text { of the fibers }\end{array}$ & E [GPa] & $\boldsymbol{\sigma}_{\max }[\mathrm{MPa}]$ & $\boldsymbol{\alpha}\left[{ }^{\circ}\right]$ \\
\hline $\mathrm{Al} / \mathrm{GFRP} / \mathrm{Al}$ & 0.3 & 0.53 & {$[0]$} & $149 \pm 37.92$ & $543 \pm 35.56$ & $140 \pm 0$ \\
$\mathrm{Al} /$ CFRP/Al & 0.3 & 0.53 & {$[0]$} & $144 \pm 80.05$ & $660 \pm 36.36$ & $145 \pm 0.29$ \\
$\mathrm{Al} /$ GFRP/Al & 0.5 & 0.66 & {$[0]$} & $86 \pm 8.48$ & $565 \pm 2.00$ & $131 \pm 0.29$ \\
& & & {$[ \pm 45]$} & $92 \pm 10.28$ & $546 \pm 15.14$ & $130 \pm 0.29$ \\
& & & {$[0 / 90]$} & $163 \pm 2.90$ & $557 \pm 8.77$ & $130 \pm 0.87$ \\
& 0.5 & 0.66 & {$[90 / 0]$} & $80 \pm 4.29$ & $557 \pm 15.68$ & 129 \\
Al/CFRP/Al & & & {$[0]$} & $99 \pm 6.43$ & $685 \pm 15.50$ & $135 \pm 0$ \\
& & & {$[0 / 90]$} & $87 \pm 2.07$ & $547 \pm 22.50$ & $129 \pm 2.22$ \\
& & & {$[90 / 0]$} & $76 \pm 4.71$ & $551 \pm 25.39$ & $130 \pm 2.83$ \\
\hline
\end{tabular}

The high damage tolerance of carbon fibers in FMLs can be attributed to their cracking mechanism (Table 2). Thus, the debonding between the fibers and the epoxy matrix produced a crack by delamination (extrinsic toughening mechanisms). Above a certain load, aluminum began to deform while the fibers remained in the elastic regime. This generated high shear stresses in the resinrich layer, which led to delamination.

Liu et al. [16] found that specimen deformation is considerable between the nose and the support. After maximum load, each curve displays a fluctuation, pointing to the occurrence of multiple failures. The specimens undergo failure under different loading conditions. Therefore, the failure mode is more complex than a shear failure. This can be explained by the fact that the lower shear strength of GLARE leads to local buckling, so the specimens deform more easily. Liu et al. [16] concluded that this phenomenon is due to lower span-to-thickness ratios (L/h ratios). Moreover, the concentration of the local compressive contact stress in the vicinity of the loading nose also contributes to the failure mode. In addition, the authors showed that the cracking forces recorded during the test were not stable at low $\mathrm{L} / \mathrm{h}$ ratios [16].

The results of the 3-point bending strength tests demonstrated that the highest values of maximum stress can be observed for the Al/CFRP/Al 0.5 laminate for the [0] fiber configuration. The laminates $\mathrm{Al} / \mathrm{CFRP} / \mathrm{Al} 0.5$ and $\mathrm{Al} / \mathrm{GFRP} / \mathrm{Al}$ of 0.5 exhibited similar values of maximum stress for the [0/90], [90/0], and [ \pm 45$]$ fiber configurations. This means that fiber configuration is of secondary importance, contrary to aluminum layer thickness, which plays a significant role here. Similar observations about FMLs with the [0] configuration have been reported by $\mathrm{Hu}$ et al. [17] and Cepeda-Jimenez [18], who tested the flexural properties of FMLs. The authors observed that the flexural strength of FMLs is approximately $700 \mathrm{MPa}$ at room temperature [18].

Comparing the laminates with respect to the MVF coefficient for the same fiber configuration, it can be observed that Young's modulus was higher for the laminates with smaller MFV regardless of the fiber type. The Al/CFRP/Al 0.5 laminates had higher Young's modulus than the $\mathrm{Al} / \mathrm{GFRP} / \mathrm{Al}$ laminates irrespective of fiber orientation. The application of load to the glass fiber specimens with the [0] and [90] orientation resulted in an increase in Young's modulus by about 1.5 times for the configuration, in which the first layer of fibers was of the [90] orientation. The carbon fiber laminate did not reveal any variations in Young's modulus depending on fiber orientation.

The results demonstrated that the deflection angles of the laminates with $0.3-\mathrm{mm}$ thick aluminum were higher than those of the laminates containing $0.5-\mathrm{mm}$ aluminum. The angles in the Al/GFRP/Al 0.5 laminate were quite similar. As regards the Al/CFRP/Al 0.5 laminate, however, the highest deflection angle of $135^{\circ}$ was observed only for the [0] fibers.

\subsection{Microstructural observations}

Figures 5-12 show the microstructure of the FML laminates after the 3-point bending test. They are in the form of "panoramic" images, i.e. a sequence of images collected from a larger area of the specimen (Figure A) and as typical microscopic images (Figures B and C). For every tested laminate configuration, the figures show the central region of the specimen where the failure of the composite layer can be observed.

Figures 5-8 show the microstructure of the FMLs with aluminum of two thicknesses: $0.3 \mathrm{~mm}$ and $0.5 \mathrm{~mm}$, 
A

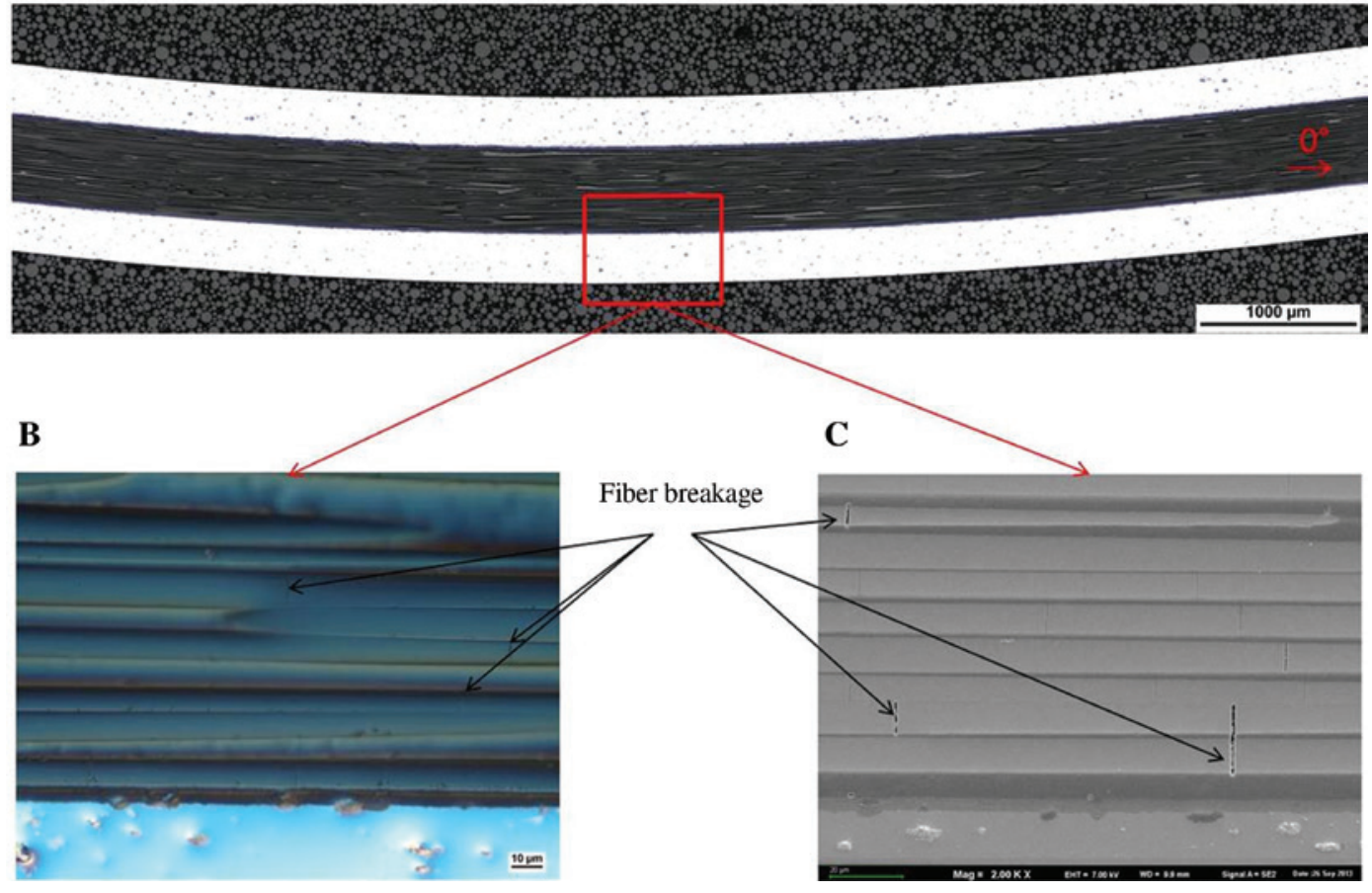

Figure 5: The microstructures of the FMLs with $0^{\circ}$ direction glass fibers and with $0.3-\mathrm{mm}$ thick aluminum. (A) Cross section and (B) and (C) broken fibers in the center of the laminate; optical microscopy and SEM.

$\mathbf{A}$

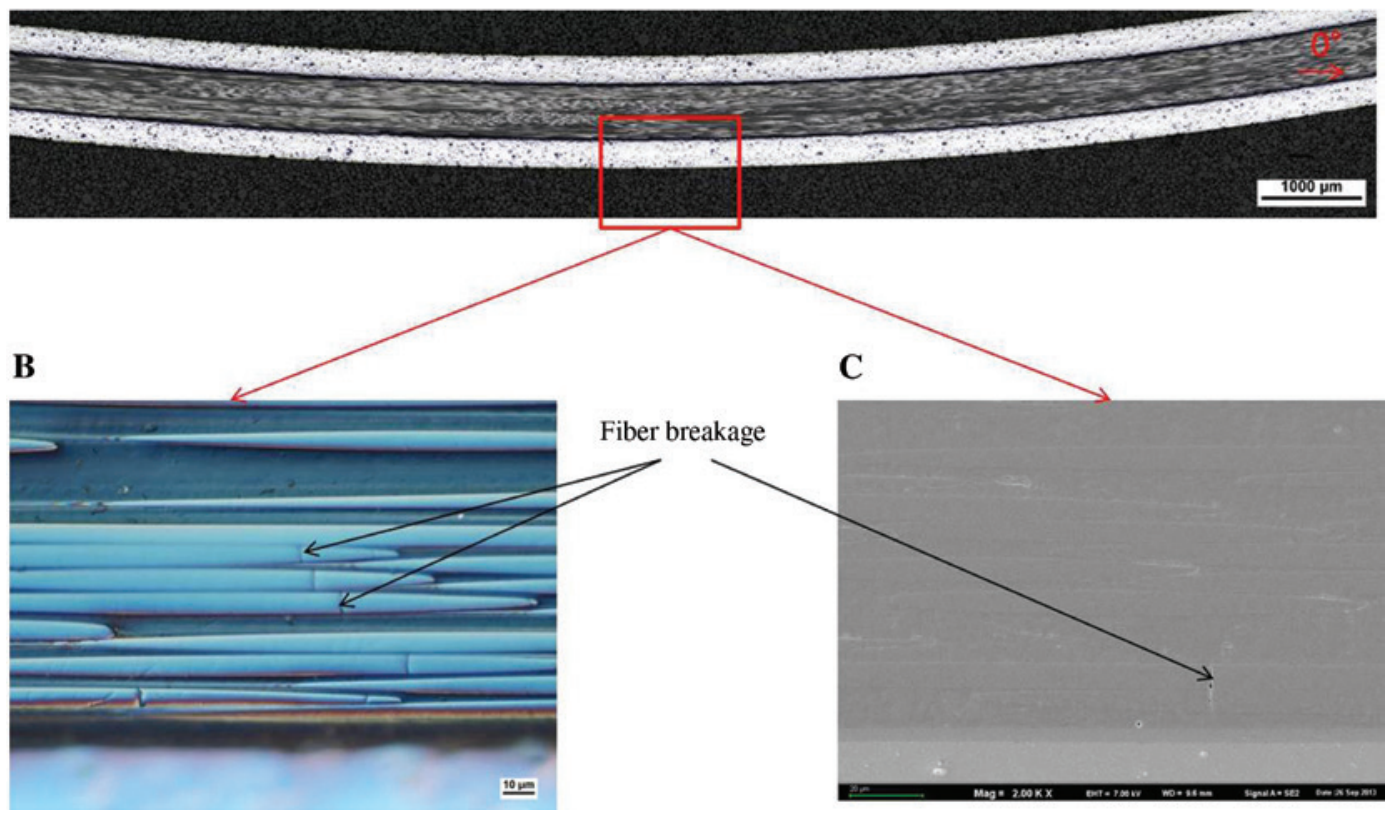

Figure 6: The microstructures of the FMLs with $0^{\circ}$ direction carbon fibers and 0.3-mm thick aluminum. (A) Cross section and (B) and (C) broken fibers in the center of the laminate; optical microscopy and SEM.

and with the [0] fiber orientation, for the glass fiber and carbon fiber laminates, respectively. Both types of laminates exhibited the same kind of failure mode, i.e. fiber breakage. No delamination can be observed between the composite and aluminum. In addition, the anodized layer did not show any sign of failure. 
A

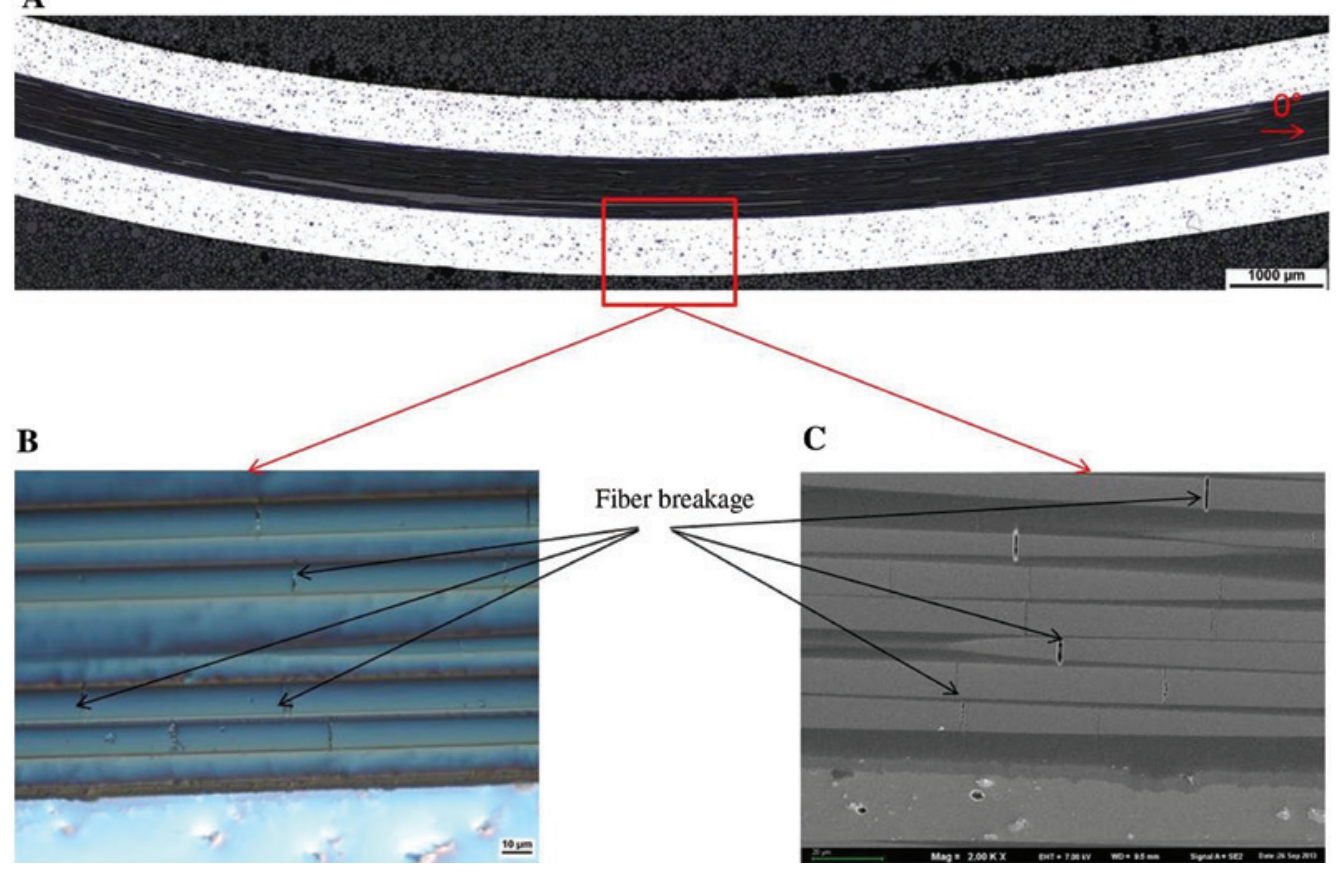

Figure 7: The microstructures of the FMLs with $0^{\circ}$ direction glass fibers and $0.5-\mathrm{mm}$ thick aluminum. (A) Cross section and (B) and (C) broken fibers in the center of the laminate; optical microscopy and SEM.

A

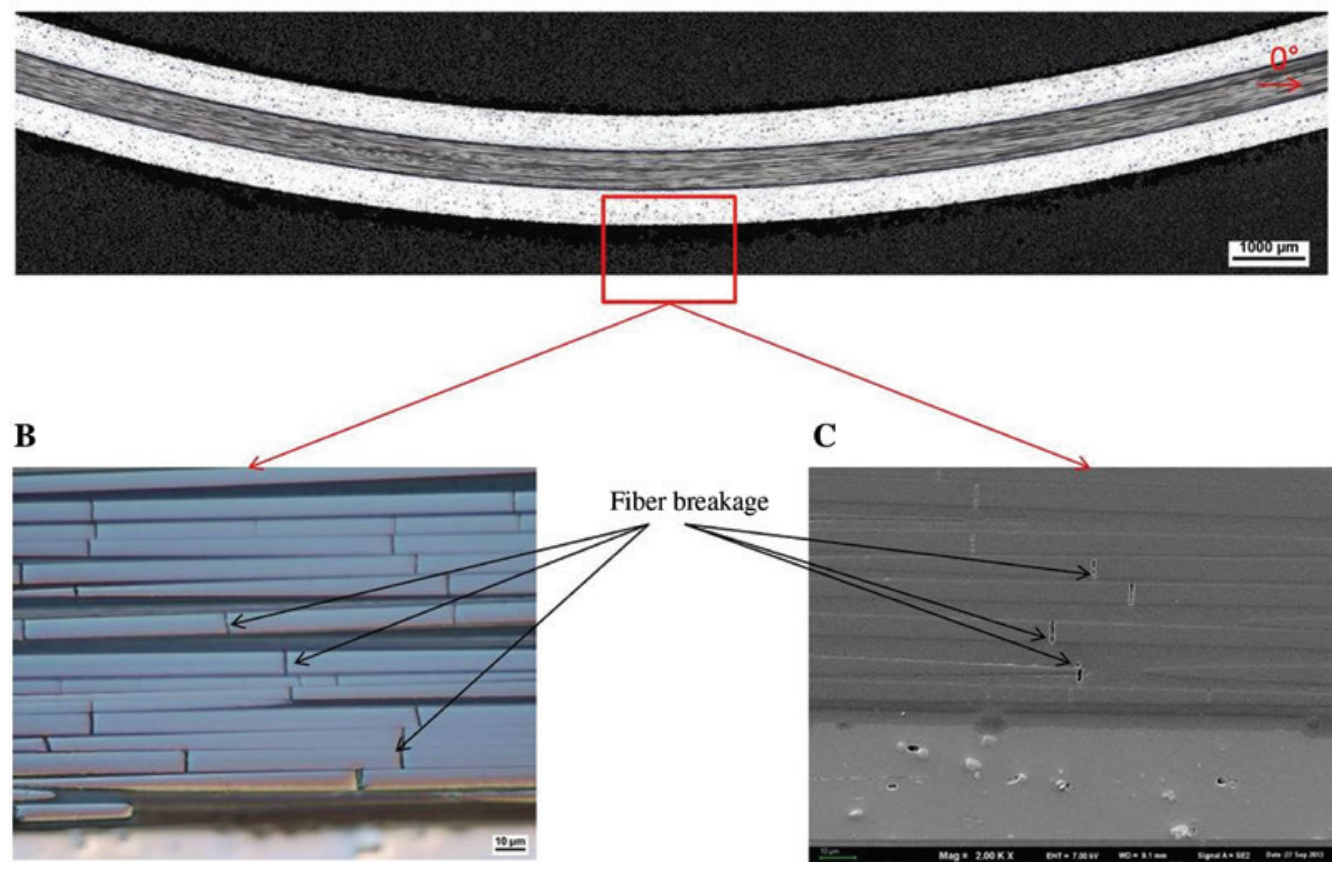

Figure 8: The microstructures of the FMLs with $0^{\circ}$ direction carbon fibers and $0.5-\mathrm{mm}$ thick aluminum. (A) Cross section and (B) and (C) broken fibers in the center of the laminate; optical microscopy and SEM.

The microstructures of the FML laminates with [0/90] fiber orientation are shown in Figures 9 and 10. This type of fiber orientation was selected for analysis due to the more significant failures of the laminates in individual layers than was the case with the [90/0] fiber orientation. The specimens exhibited similar failure 
A

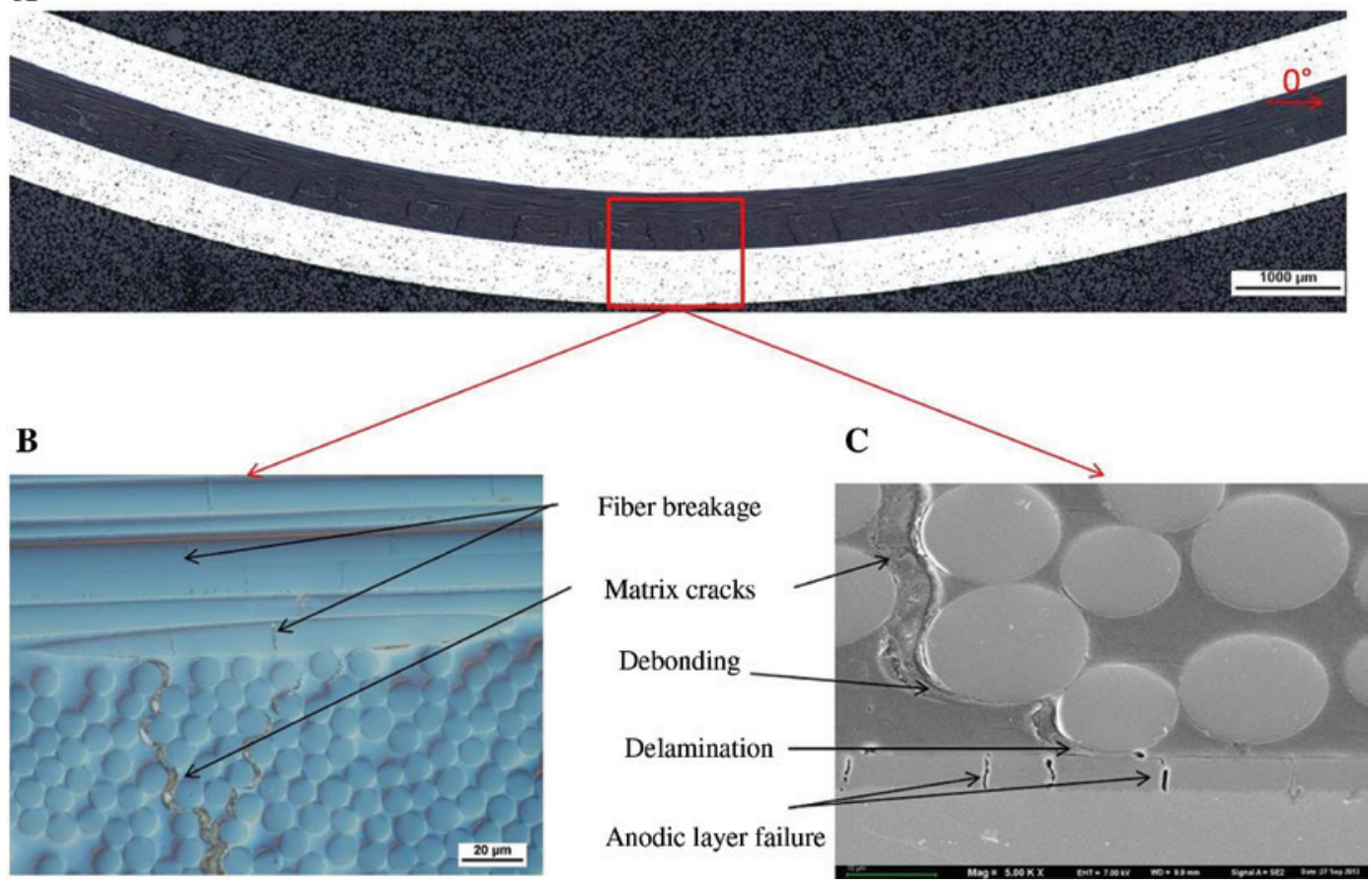

Figure 9: The microstructures of the FMLs with $0 / 90^{\circ}$ glass fibers and $0.5-\mathrm{mm}$ thick aluminum. (A) Cross section, (B) broken fibers and failure of the matrix, (C) delamination and cracks in the matrix and cracks in the anodic layer; optical microscopy and SEM.

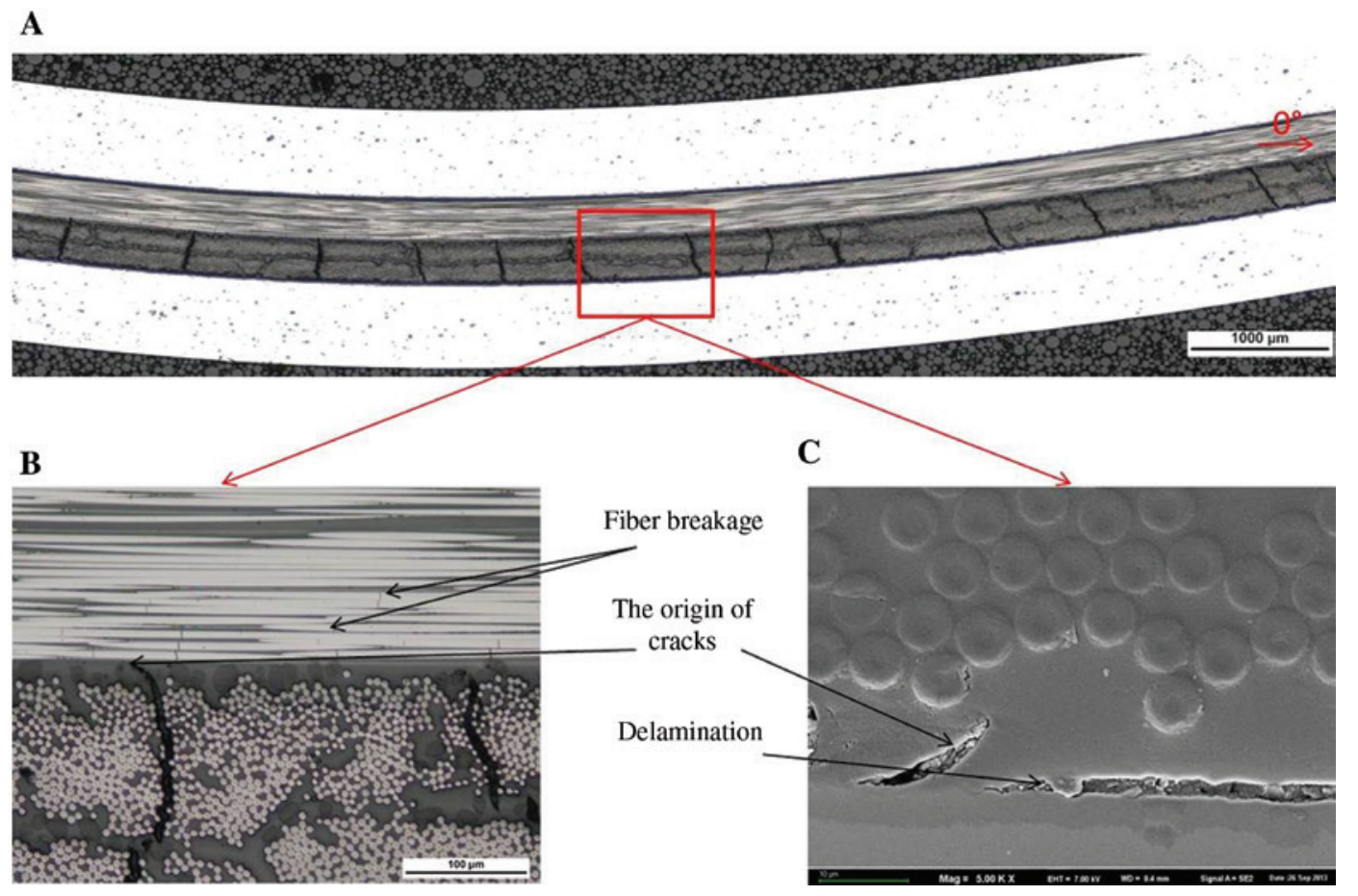

Figure 10: The microstructures of the FMLs with $0 / 90^{\circ}$ carbon fibers and 0.5-mm thick aluminum. (A) Cross section, (B) broken fibers and cracks in the matrix, and (C) delamination and failure of the matrix; optical microscopy and SEM.

modes regardless of fiber type. The failure consisted of fiber breakage in the layer with [0] fibers. Debonding occurred on the matrix/fiber interface. The matrix underwent failure in the layer consisting of [90] fibers. Delamination occurred between the anodized aluminum layer and the composite material. 
A
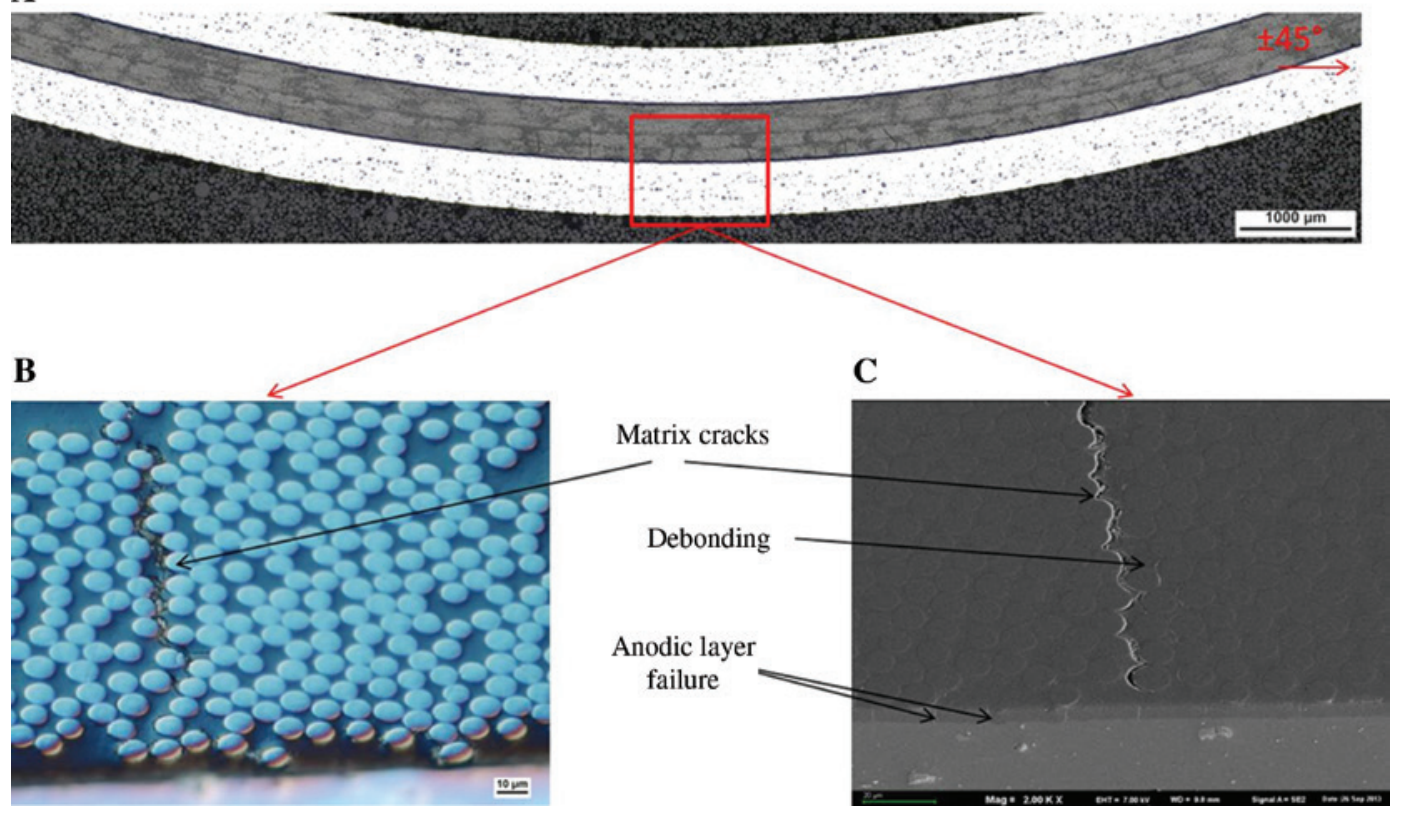

Figure 11: The microstructures of the FMLs with $\pm 45^{\circ}$ glass fibers and 0.5 - $\mathrm{mm}$ thick aluminum. (A) Cross section, (B) delamination and cracks in the matrix, and (C) cracks and debonding in the matrix and cracks in the anodic layer; optical microscopy and SEM.

A
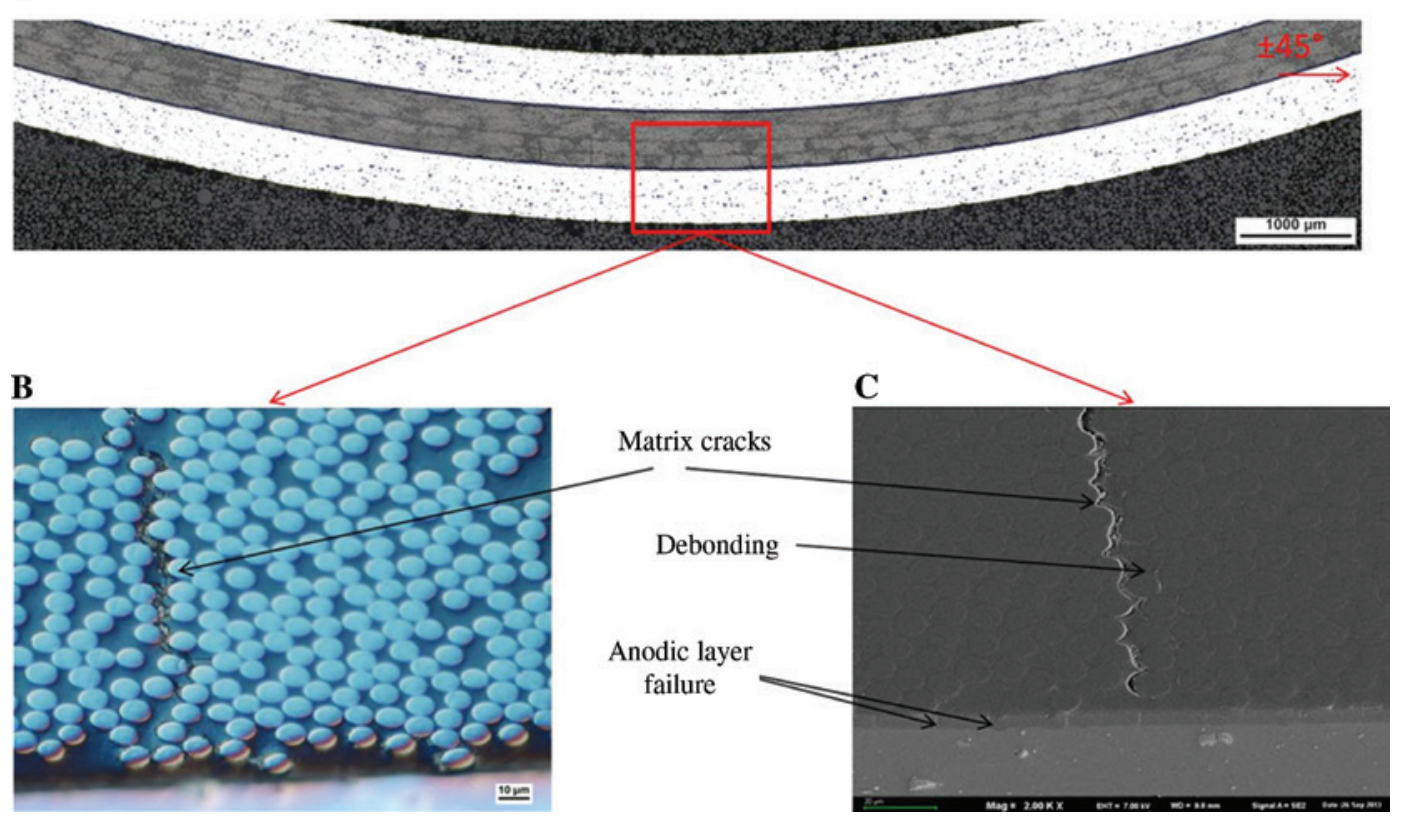

Figure 12: The microstructures of the FMLs with $\pm 45^{\circ}$ carbon fibers and $0.5 \mathrm{~mm}$ thickness of aluminum. (A) Cross section, (B) cracks in the matrix, and (C) cracks and debonding in the matrix-fibers and cracks in the anodic layer; optical microscopy and SEM.

The FMLs with the $[ \pm 45]$ orientation (Figures 11 and 12), both of carbon and glass fibers, revealed the presence of delamination between the polymer layer and the anodic layer. The anodic layer exhibited a failure mode in the form of transverse cracks, indicating the occurrence of debonding on the fiber-matrix interface.

\section{Discussion}

Examining Figures $8-12$, it can be observed that the debonded fibers act as unbroken ligaments bridging the main failure, and additional bending deformation must occur to crack them. The examination of the failure of 
microstructures revealed the presence of mechanisms similar to the classical "fiber bridging" mechanism of cracking. The high damage tolerance of the FMLs containing glass and carbon fibers results from their cracking mechanism. The debonding between the fibers and the epoxy matrix produces cracking by delamination. This is an extrinsic toughening mechanism that has also been reported by Cepeda-Jimenez [18]. Aluminum tends to start deforming while the fibers are still in the elastic regime. This phenomenon is caused by the high shear stresses in the resin-rich layer [19], which leads to delamination. As the deformation proceeds, the delamination shifts toward the support point of the fibers during the bending test; further deformation and stresses contribute to the fiber breakage [19]. Some authors reported that a permanent set of FMLs results from the plasticity of aluminum and is not caused by delamination of the FML layers [20]. Carillo et al. [21] reported the same after having examined FML specimens for deformation and failure modes. None of the specimens showed any visible signs of cracking. On closer inspection, one can observe a complete lack of delamination on the composite/metal interface, thereby proving that none of the constituents of the FML failed during the testing of the [0] configuration. Similar observations were made with respect to the two types of aluminum thickness, specifically on the [0/90] and [ \pm 45$]$ configurations of the FML specimens loaded in flexure, where it is evident that the composite laminate is damaged throughout the volume of the sample. The same observations were made by Carillo [21], who conducted flexural tests on the [ $\pm 0 / 90]$ and $[ \pm 45]$ configurations, indicating that the fiber orientation only has a secondary effect on the properties of the FMLs, with the maximum stress and strain at failure being similar in both cases [21].

Some researchers, for example, Cepeda-Jimenez [22], observed and concluded that, in the GLARE laminate, the ultimate strain of the fibers controls the ultimate flexure stress. The material presents several cases of delamination, together with extensive plastic deformation of the Al 2024 layers that are necessary to induce crack renucleation. Mortell et al. [23] demonstrate that the GLARE laminate first shows a decrease in load, which coincides with the cracking of the notched Al 2024 layer until the crack is constrained in the resin layer by the debonding of the glass fibers with the epoxy resin. Bienias et al. [24] observed similar phenomena in the structure failure as plastic deformation, especially of the aluminum layers, matrix cracking with delamination, as well as fiber breakage on the aluminum composite interface. In addition, they observed that FMLs with carbon layers under bending show the presence of a vertical crack occurring in the lower laminate layers caused by tensile stresses. The microscopic examination of the tested FMLs and composites revealed that matrix cracking and delamination are two prevailing failure modes in the standard carbon composites as well as in FMLs. The presence of delamination can also be observed on the metal-composite interface, with permanent plastic deformation and metal layer cracking depending on the impact energy [25].

Generally, the fiber-matrix interface is the most likely location of failure initiation due to its relative weakness [23]. Delamination may be caused by the presence of matrix cracks and interlayer shear stress alongside the interface, stiffness incompatibility between adjacent layers, layer grouping, and laminate deformation [26, 27]. Wu et al. [13] said that different failure deflections of variants are caused by varying lay-up configurations of glass/ epoxy layers; in other words, the fiber direction also affect the interlaminar failure behavior. Fibers along the length direction of the specimen dominate in the load capacity of the laminates and contribute to bending modulus. Furthermore, Turner et al. [28] pointed out that, during the 3-point bending tests, stress concentrations have been reported to cause the early-onset microcracking of the matrix and the subsequent, localized non-linearity, potentially leading to total failure of the beam [29]. The load concentration in the 3-point bending test leads to a combination of bending with shear stresses [29], causing difficulty in the isolation of either one. Thus, for composites with high levels of orthotropy, a flexural and a twisting curvature is introduced throughout the beam length, which adds to the complication during 3-point bending tests [30].

The elastic region in the FML laminates show better yield stress and stiffness in bending as the number of steel layers increase, similar to the findings of Khalili et al. [2]. They observed the following trend: given that the applied aluminum alloy is weak, the location of these layers at the locations far away from the neutral axis of the samples would not help increase the bending strength and stiffness of the FML composites. They concluded the same that FMLs show flexible behavior. Khalili et al. [2] added the comparison with the composite structures and concluded that FMLs are indeed more flexible. According to Racz and Vas, the flexural properties of unidirectional carbon/epoxy specimens subjected to 3-point bending showed that unidirectional composites exhibit a transition in the failure mode from shear delamination to tensile or compressive failure with an increasing span-to-thickness ratio (L/h) [31]. Fleck and Liu [32] found that the difference in compressive strengths for a beam subjected to bending and a beam under direct compression is small for 
the beams with a thickness that is over 1000 times higher than the fiber diameter.

With regards the bending stress and failure of the FMLs, the thicknesses of both the composite laminate and aluminum sheets (between $0.3 \mathrm{~mm}$ and $0.5 \mathrm{~mm}$ ) plays an important role. The authors claim that metal properties play a more significant role than fiber configuration [33]. Some authors concluded that the maximum stress in the 3-point bending test decreases as the thickness of aluminum sheet increases [34-36]. This phenomenon was not observed in the present study. The type of fibers and the direction of composite layers play an important role. Young's modulus is higher in the aluminum layers with 0.3-mm thickness than those with a 0.5-mm thickness, irrespective of the place of load application.

\section{Conclusions}

The study investigated the mechanical properties, failure, and characteristics of the internal structure of FMLs subjected to 3-point bending. The mechanism of failure of the internal structure is very complex and is related with the internal degradation of the composite layers and the plastic deformation of the FMLs with carbon and glass fibers. One can observe the same mechanisms of failure irrespective of fiber type and aluminum thickness. The tested laminates show the following failure modes: fiber breakage, matrix cracking, fiber/matrix debonding, delamination, and failure of the anodic layer. The anodic layer on aluminum with a 0.5 -mm thickness may undergo failure. One can observe a characteristic debonding occurring on the fiber-matrix interface in the composite layers. A failure mode in the form of delamination can be observed between the composite layers and the surface of the anodized metal. The high damage tolerance of carbon fiber in FMLs is mainly due to their resistance to cracking. Thus, the debonding between the fibers and the epoxy matrix leads to the cracking by delamination (extrinsic toughening mechanisms). This generates high shear stresses in the resin-rich layer, which could promote delamination. In addition, the maximum strain of the fibers affects their maximum flexural stress.

The behavior of aluminum under compressive and tensile stresses during bending prevent the failure of the FML. This means that the thickness of the aluminum layer is important, but the fiber type and composite layer orientation are also significant, particularly when the fibers are in the [0] direction. There are no differences in failure modes observed for the $[ \pm 45],[0 / 90]$, and [90/0] layers, which means that the fiber orientation exerts only a secondary effect on the properties of the FML. As regards the fiber type, the FMLs with carbon fibers exhibit higher strength than those containing glass fibers.

Acknowledgments: This research project was financed by the National Science Center of Poland under Grant no. 2011/01/ST8/07685.

\section{References}

[1] Vlot A. GLARE ${ }^{\circledR}$ History of the Development of a New Aircraft Material, Kluwer Academic Publishers: Delft, The Netherlands, 2001.

[2] Khalili SMR, Mittal RK, Kaliba GS. Mater. Sci. Eng. A 2005, 412, 1-2, 137-140.

[3] Yeh JR. Eng. Fract. Mech. 1988, 30, 827-837.

[4] Marissen R. Adv. Fatigue Sci. Technol. 1989, 159, 697-703.

[5] Afaghi-Khatibi A, Lawcock G, Ye L, Mai YW. Comput. Methods Appl. Mech. Eng. 2000, 185, 2-4, 173-190.

[6] Bazhenov SL. Composites 1995, 26, 11, 757-765.

[7] Greenhalgh ES. Failure Analysis and Fractography of Polymer Composites, Woodhead Publishing Limited and CRC Press LLC: USA, 2009.

[8] Czapski P, Kubiak T. Fibres Text East Eur. http://dx.doi. org/10.5604/12303666.1161764.

[9] Jones RM. Mech. Compos. Mater. http://dx.doi.org/10.1007/ BF00611782.

[10] Jones RM. J. Compos. Mater. 1976, 10, 342-354.

[11] Mujika F, Carbajal N, Arrese A, Mondragón I. Polymer Test 2006, 25, 766-771.

[12] Carbajal N, Mujika F. Polym Test 2009, 28, 150-156.

[13] Wu G, Yang JM. Failure Structural Materials. doi: 10.1007/ s11837-005-0067-4.

[14] Pahr DH, Rammerstorfer FG, Rosenkranz P, Humer K, Weber HW. Composites Part B 2002, 33, 125-132.

[15] Remmers JJ, De Borst R. Compos. Sci. Technol. 2001, 61, 2207-2213.

[16] Liu Ch, Du D, Li H, Hu Y, Xu Y, Tian Y, Tao G, Tao J. Composites Part B 2016, 97, 15, 361-367.

[17] Hu YB, Li HG, Cai L, Zhu JP, Pan L, Xua J, Tao J. Composites Part B 2015, 69, 587-591.

[18] Cepeda-Jimenez CM, Alderliesten RC, Ruano OA, Carreno F. Compos. Sci. Technol. 2009, 69, 3-4, 343-348.

[19] Carrillo JG, Cantwell WJ. Compos. Sci. Technol. 2007, 67, 1684-1693.

[20] Kamocka M, Zglinicki M, Mania RJ. Composites Part B 2016, 91, 135-143.

[21] Carrillo JG, Cantwell WJ. Mech. Mater. 2009, 41, 828-838.

[22] Cepeda-Jiméneza CM, Pozuelob M, García-Infantaa JM, Ruanoa OA, Carren o F. Mater. Sci. Eng. A 2008, 496,1-2, 133-142.

[23] Mortell DJ, Tanner DA, McCarthy CT. Compos. Struct. 2016, 149, 33-40.

[24] Bieniaś J, Jakubczak P, Surowska B, Dragan K. Arch. Civil Mech. Eng. 2015, 15, 4, 925-932.

[25] Bieniaś J, Jakubczak P, Dadej K. Compos. Struct. 2016, 152, 3399-3348. 
[26] Abrate S. Impact on Composite Structures, Cambridge University Press: New York, 1998, pp 135-160.

[27] González EV, Maimí P, Camanho PP, Lopes C, Blanco N. Compos. Sci. Technol. 2011, 71, 805-817.

[28] Turner P, Liu T, Zeng X. Compos. Struct. 2016, 142, 286-297.

[29] Khashaba U, Seif M. Compos Struct 2006, 74, 440-448.

[30] UNE-EN ISO 14130:1999: Fibre-reinforced plastic plastic composites. Determination of apparent interlaminar shear strength by short beam method, 1999 .
[31] Racz ZS, Vas LM. Compos. Interfaces 2005, 12, 325-339.

[32] Fleck NA, Liu D. Eur. J. Mech. A 2001, 20, 23-37.

[33] Ostapiuk M, Surowska B, Bieniaś J, Majerski K. Compos. Theory Pract. 2013, 13, 237-240.

[34] Wisnom MR, Atkinson JA. Compos. Struct. 1997, 38, 405-412.

[35] Whitney JM, Knight M. Exp. Mech. 1980, 17, 211-216.

[36] Jackson KE, Kellas S, Morton J. J. Compos. Mater. 1992, 26, 2674-2705. 